\title{
Fabrication of Specially Designed Novel Mold for Casting of Perindopril Erbumine Mouth Dissolving Film
}

\author{
Vivekanand K. Chatap* Abhijit M. Karale, Pramod Wagh, Prashant K. Deshmukh, Savita D. Patil \& \\ Sanjay B. Bari \\ Post Graduate Department of Pharmaceutics \& Industrial Pharmacy, H. R. Patel Institute of Pharmaceutical Education and Research, \\ Shirpur, Maharashtra, India-425405 \\ *Corresponding Author: chatap@rediffmail.com
}

Copyright (C) 2013 Horizon Research Publishing All rights reserved.

\begin{abstract}
In present investigation attempt was made to design novel mold with aim to overcome the problems occurs during the casting of mouth dissolving films. Placebo and Perindopril Erbumine containing mouth dissolving film (MDF) were prepared with Pullulan, HPMC E-15 as film forming agent and other excipient by solvent casting method on specially design mold and regular petri dish. The HPMC E-15 125mg and Propylene Glycol $30 \mu \mathrm{ml}$ as plasticizer contains MDFs formulation (H2) were found to be optimized when compared with Pullulan on the basis of physical evaluation parameters like weight variation, drug, thickness in the range $0.01-0.03 \mathrm{~mm}$, disintegration time in $<17 \mathrm{sec}$. And release of drug from the film was found to $<60 \mathrm{sec}$ and other parameters were found within acceptable limits. The prepared optimized stable mouth dissolving films were characterized by SEM, FT-IR, DSC etc. And various new equipments were used first time in PMDFs preparation for cutting, pill-out and water level indicator for balancing novel mold in the oven, which was widely used in other field like engineering and physics. Especially design mold for casting of the film was found to be more efficient than regular petri dish due to easily scale up and avoid problems occurs during preparation of stable mouth dissolving film which leads to reduce the wastage of active ingredients and excipients.
\end{abstract}

Keywords Novel mold, Solvent Casting Method, Pullulan, \& HPMC E-15, Perindopril Erbumine and Mouth Dissolving Film

\section{Introduction}

Mouth dissolving films (MDFs) that disintegrate and dissolve upon contact with a wet surface within seconds in oral cavity is gaining increasing popularity day-by-day (1-4). Due to its easy administration, avoidance of water use, (4-7) and first pass metabolism; quick onset of action, and convenient way of dosing medications, $(5,7,8)$. These MDFs are not merely meant for special population groups with swallowing difficulties like children and the elderly, but also for the general population. $(3,4,7)$ The MDFs allow multidirectional drug transport, but by applying a backing layer even unidirectional drug transport can be achieved. Drug loaded MDF were reported by various researchers for various physiological and neurological conditions like dysphasia, motion sickness, allergic attacks, or coughing, hand tremors, rheumatoid arthritis, degenerative arthritis and gout $(2,4,5,7)$.

The MDF was prepared by various method like rolling method, hot melt extrusion, solid dispersion extrusion, solvent casting method, semisolid casting method (10). Among these methods, solvent casting method is reported widely in literature (11), due to its simplicity and convenience but these methods have some limitations like deposition of drug solution at the edges of petri dish, cracking of the film, un-uniform distribution of excipient, variation in thickness and wastage during cutting of film and wastage of drug solution.

In the light of the above literature an effort was made for designing of novel mold (NM) for casting MDFs prepared by solvent casting method. In this research, Perindopril Erbumine (PEM) an ACE inhibitor, which is widely used in the treatment of high blood pressure was selected as model drug for preparation of MDFs. The effect of plasticizer and film forming agent concentration was examined and further characterized by different evaluation parameters like disintegration time, dissolving time, thickness, weight variation, content uniformity, surface $\mathrm{pH}$, tear resistance, folding endurance, percent elongation, and tensile strength. $(7,8,9)$ and first time we're using new equipments required for cutting, stripping down, leveling of NM during preparation of films.

\section{Material}

Perindopril Erbumine (PEM) was obtained as a gift sample from Dr. Reddy's Lab, R and D, Hyderabad. Pullulan (Hayashibara, Okayama, Japan) was generously gifted by Gangwal Chemical Pvt. Ltd, Mumbai India. Neotame was 
obtained as a gift sample from Kawarlal and Co. Chennai, India. All other chemicals and reagents used were of analytical grades and used as received.

\section{Method}

\section{Preparation of placebo mouth dissolving film}

Placebo MDFs (PMDFs) were prepared by commonly used solvent casting method. In this method water-soluble polymers (HPMC E-15 and Pullulan as film former) were dissolved in distilled water and other excipients like Propylene glycol and PEG-400 as plasticizer, Neotame as sweetening agent, Amaranth die as coloring agent and citric acid as saliva stimulating agent were added with continuous stirring and finally casted into regular shape (circular) in petridish $(10,11)$ and dried in hot air oven at optimized $50^{\circ} \mathrm{C}$ for next $24 \mathrm{~h}(4,12)$ and cut each PMDF in size $2 \times 2 \mathrm{~cm}$. and stored in dry and well-closed container. $(12,13)$ and evaluated by different evaluation parameters.

\section{Fabrication of PMDF using conventional technique}

During preparation of PMDF some defects were observed in solvent casting method like deposition of solution at the edges of petri dish, cracking of film, un-uniform distribution of excipients, variation in thickness and wastage during cutting of film, summarized in (Fig.1) In this method, solution was cast in regular shape (circular) using petri dish. Most of the MDFs were square in shape; this method resulted in only $55 \%$ practical yield and $45 \%$ loss during preparation film. The wastage occurred during cutting of the film was significant. Consequently there was a need of modification of this technique for casting of the film, which will reduce the wastage of active ingredient and other excipients.

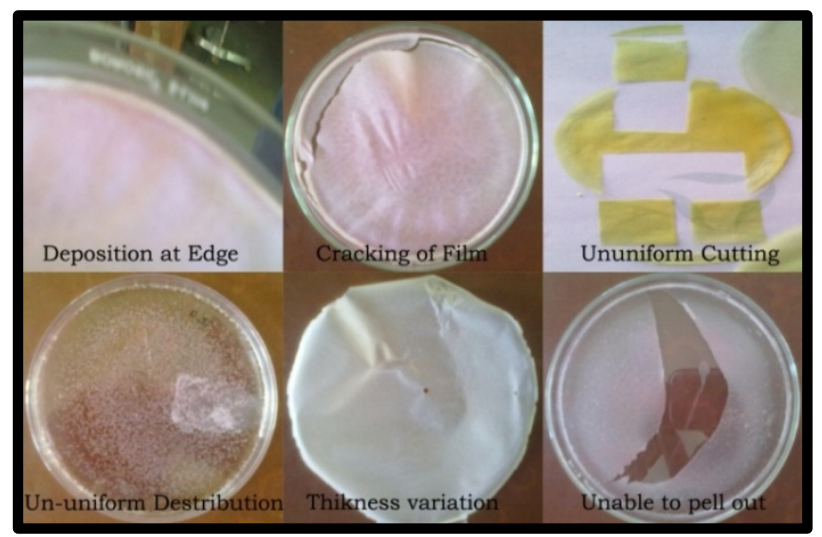

Figure1. Defects in mouth dissolving films

\section{Design of Specially Design Novel mold}

The mold was fabricated by using thick glass which provides resistance to thermal stress, with thickness of $0.5 \mathrm{~cm}$ with dimension of $30 \times 30 \mathrm{~cm}$. Left the space $5 \times 5 \mathrm{~cm}$ all sides and fixed glass plate with the help of Araldite glue which having thickness $0.4 \mathrm{~cm}$ and width $1 \mathrm{~cm}$, square shape novel mold were design having inner size diameter $19 \times 19 \mathrm{~cm}$ area, which was used for casting of the film (Fig.2). During the casting of film on NM were using water leveling meter to achieve the proper thickness of all film, which is widely used for the wall leveling purpose in construction of buildings, Roll and Draw scale for cutting of film which is widely used in engineering drawing and forceps were used for pill-out of film.

B

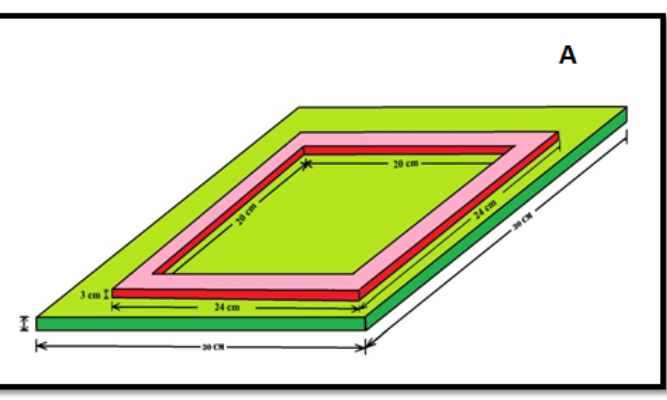

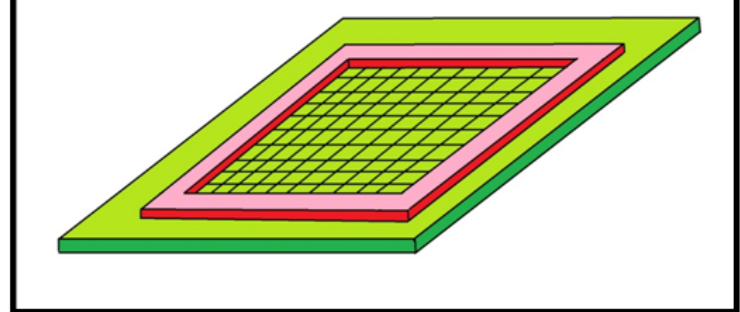

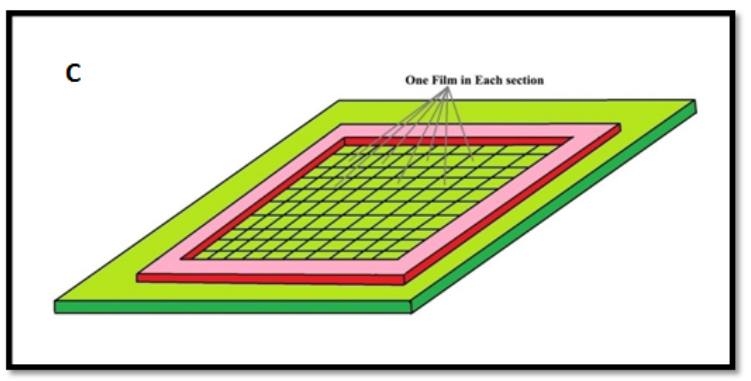

Figure 2. Designed novel mould for mouth dissolving film 
Table 1. Effect of HPMC E15 \& Pullulan as film forming agent

\begin{tabular}{|c|c|c|c|c|c|c|c|c|c|c|}
\hline Formulation & $\begin{array}{c}\text { H1 } \\
\text { P1 }\end{array}$ & $\begin{array}{c}\text { H2 } \\
\text { P2 }\end{array}$ & $\begin{array}{c}\text { H3 } \\
\text { P3 }\end{array}$ & $\begin{array}{c}\text { H4 } \\
\text { P4 }\end{array}$ & $\begin{array}{c}\text { H5 } \\
\text { P5 }\end{array}$ & $\begin{array}{c}\text { H6 } \\
\text { P6 }\end{array}$ & $\begin{array}{c}\text { H7 } \\
\text { P7 }\end{array}$ & $\begin{array}{c}\text { H8 } \\
\text { P8 }\end{array}$ & $\begin{array}{c}\text { H9 } \\
\text { P9 }\end{array}$ & $\begin{array}{c}\text { H10 } \\
\text { P10 }\end{array}$ \\
\hline HPMC E-15 [H1-H10] & 100 & 125 & 150 & 175 & 200 & 225 & 250 & 275 & 300 & 400 \\
\hline PULLULAN [P1-P10] & 350 & 400 & 450 & 500 & 550 & 550 & 600 & 650 & 700 & 750 \\
\hline Dist. Water (ml) & 14 & 14 & 14 & 14 & 14 & 14 & 14 & 14 & 14 & 14 \\
\hline
\end{tabular}

Table 2. Effect of Polyethylene Glycol \& PEG400 as plasticizer

\begin{tabular}{|c|c|c|c|c|c|c|c|c|}
\hline Ingredient $(\mathrm{mg})$ & $\begin{array}{l}\text { A1 } \\
\text { B1 }\end{array}$ & $\begin{array}{l}\text { A2 } \\
\text { B2 }\end{array}$ & $\begin{array}{l}\text { A3 } \\
\text { B3 }\end{array}$ & $\begin{array}{l}\text { A4 } \\
\text { B4 }\end{array}$ & $\begin{array}{l}\text { A5 } \\
\text { B5 }\end{array}$ & $\begin{array}{l}\text { A6 } \\
\text { B6 }\end{array}$ & $\begin{array}{l}\text { A7 } \\
\text { B7 }\end{array}$ & $\begin{array}{l}\text { A8 } \\
\text { B8 }\end{array}$ \\
\hline HPMC E15 [A1-A8] & 125 & 125 & 125 & 125 & 125 & 125 & 125 & 125 \\
\hline Pullulan [B1-B8] & 450 & 450 & 450 & 450 & 450 & 450 & 450 & 450 \\
\hline Propylene Glycol & 10 & & 20 & & 30 & & 40 & \\
\hline PEG-400 & & 10 & & 20 & & 30 & & 40 \\
\hline Distilled water $(\mathrm{ml})$ & 14 & 14 & 14 & 14 & 14 & 14 & 14 & 14 \\
\hline
\end{tabular}

\section{Fabrication of PMDF using novel mold}

Modify the existing solvent casting method which is required for specially designed novel mold, In this method, Divide equal amounts of solvent (water) in two portions denoted as Part (A) and Part (B). In Part (A), distilled water used as solvent, mix film forming agent HPMC E-15 and Pullulan in different concentration of $125-750 \mathrm{mg}$ and 450-950 $\mathrm{mg}$ respectively and study the effect of film forming agent on film formation, shown in (Table 1) and Propylene glycol and PEG-400 as a plasticizer in 10,20,30,40 $\mu / \mathrm{ml}$ and study the effect of plasticizer on film formation, shown in (Table 2) Neotame, Amaranth die and citric acid was used as sweetening, coloring and saliva stimulating agent respectively. In Part (B) $72 \mathrm{mg}$ of active ingredient (Perindopril Erbumine) was dissolved in distilled water for preparation of 18 films containing $4 \mathrm{mg}$ of dose and mixed both part carefully with continuous stirring on magnetic stirrer at $500 \mathrm{rpm}$ for $2 \mathrm{~h}$. Dispersion was carefully cast in novel mold and kept in hot air oven for drying at $60^{\circ} \mathrm{C}$ for 24 hours (Fig.2). The PMDFs were cut and pill-out into size $2 \times 2 \mathrm{~cm}$ containing $4 \mathrm{mg}$ of perindopril erbumine with help of roll and draw scale and forecep respectively. Prepared PMDFs were stored in the dry and airtight container. The outcome of the film forming agent and plasticizer concentration was examined and various new equipments were used first time in PMDFs preparation for cutting, pill-out and water level indicator for balancing novel mold in the oven, which was widely used in other field like engineering and physics

\section{Evaluation of MDF}

\section{Thickness}

Thicknesses of PMDF were measured by Digimatic Caliper (Mitutoyo, Japan) with range $0-10 \mathrm{~mm}$ and resolution $0.01 \mathrm{~mm}$. Anvil of the thickness gage was lifted and $4 \mathrm{mg}$ single dose PMDF was inserted after making sure that the pointer was set to zero. The MDF was held on the anvil and the reading on the dial was noted. The average of three readings was taken as mean thickness. (14)

\section{Weight variation}

The prepared PMDFs were evaluated for their uniformity of weights. Ten films were weighed on digital weighing balance (AS-220/X, RADWAG wagi Elektroniczne, Polland) individually and average weight was calculated. Individual film weights were compared to the average weight. (15)

\section{Drug content}

Equivalent to 4mg PMDF was dissolved in 4ml distilled water and sonicated for $15 \mathrm{~min}$. This solution was filtered through the whatmann number 1 filter paper. PMDF extract $\left(1 \mathrm{mg} \mathrm{mL} \mathrm{m}^{-1}\right)$ was diluted with water to give a final concentration $\left(500 \quad \mu \mathrm{g} \quad \mathrm{mL}^{-1}\right)$ and determined the concentration of Perindopril Erbumine by using UV/VIS spectrophotometer (Shimadzu-1800) was found to be $\lambda \max$ $213 \mathrm{~nm}$, which was coming under the vacuum range of UV/VIS spectrophotometer, thus Chandra Bala Sekaran et al spectrophotometric method was used to increase $\lambda \max$ $213 \mathrm{~nm}$ for analysis of Perindopril Erbumine. In this method $1 \mathrm{~mL}$ of $0.5 \mathrm{~N} \mathrm{HCl}$ and $0.5 \mathrm{ml}$ of $0.5 \%$ Bromophenol blue was transferred in suitable aliquot and mixed well. The funnels were shaken vigorously with $5 \mathrm{~mL}$ of chloroform for 
2 min and then allowed to stand for clear separation of the two phases. The chloroform phase thus separated was transferred into a $10 \mathrm{~mL}$ volumetric flask. Then the extract was made up to the mark with chloroform and mixed well. The absorbance of the chloroform phase was measured at $\lambda \max 425 \mathrm{~nm}$ against a reagent blank prepared similarly omitting the drug.(15).This spectrophotometric measured $\lambda \max 425 \mathrm{~nm}$ were used for further analysis of Perindopril Erbumine

\section{Content uniformity}

Ten PMDFs equivalent to $40 \mathrm{mg}$ were dissolved in $40 \mathrm{ml}$ and sonicated for $15 \mathrm{~min}$. this solution was filtered through the whatmann number 1 filter paper. PMDF extract (1mg $\mathrm{ml}^{-1}$ ) was diluted with water to give a final concentration (500 $\mu \mathrm{g} \mathrm{mL}^{-1}$ ). Above mention spectrophotometric method was used for analysis of content uniformity of Perindopril Erbumine. The content uniformity of PMDF, and the content of Perindopril Erbumine was determined by UV/VIS spectrophotometer (Shimadzu- 1800) at $\lambda \max 425 \mathrm{~nm}$. In USP27, the contents of major component in the preparation should be within a range between $85 \%$ and $115 \%$, and the relative standard deviation should be less than or equal to $6.0 \%$.

\section{Surface pH:}

The prepared PMDF was placed in a petri dish and moistened with $0.5 \mathrm{ml}$ of distilled water and kept it for 30 second. The $\mathrm{pH}$ was noted after bringing the electrode of the $\mathrm{pH}$ meter in contact with the surface of the film and allowing equilibration for $1 \mathrm{~min}$. The average of three determinations for each film was done.

\section{Disintegration Time:}

In vitro disintegration time is determined visually in a glass dish of $25 \mathrm{ml}$ distilled water with swirling every $10 \mathrm{Sec}$. The disintegration time is the time when the film starts to split or disintegrates. (10)

\section{Tensile strength}

Tensile strength of PMDF was analyzed on tensile grip was fixed to the base of the Brookfield CT3 Texture Analyzer, while the other one was attached to the load cell, sample was placed between both tensile grips on the Texture Analyzer, Rupture force was taken as the maximum force required to break the sample and the tensile strength was calculated by the following equation. $(3,13,17,18)$

$$
\text { Tensile strength }=\frac{\text { Rupture force }}{\text { Thickness } \times \text { width }}
$$

Percentage elongation: Percentage elongation of PMDF was determined by using Brookfield CT3 Texture Analyzer When stress applied $500 \mathrm{~g}$ trigger load, speed $0.3 \mathrm{~mm} / \mathrm{sec}$, PMDF sample was stretches with final load $73 \mathrm{~g}$ and work $35.5 \mathrm{~mJ}$ required for deformation at peak load $0.84 \mathrm{~mm}$ was referred to as strain. Strain is basically the deformation of strip divided by the original dimension of the sample.
Generally elongation of strip increases as the plasticizer content increases. (13)

$$
\% \text { Elongation }=\frac{\text { Iincrease in length of strip } \times 100}{\text { Initial length of strip }}
$$

\section{Tear Resistance}

Tear resistance of PMDF was determined by using Brookfield CT3 Texture Analyzer Principally low rate of loading $51 \mathrm{~mm}$ (2 in.) / $\mathrm{min}$ is in employment to determine the strength to initiate tearing. The maximum tension necessary to tear the variety is recorded as the tear resistance value in Newton's. and Tear resistance of film is a composite of its final resistance to break. (19)

\section{Folding endurance}

Folding endurance was determined by repeated folding of the strip at the same place till the strip breaks. The number of times the film was folded without breaking is computed as the folding endurance value.

\section{In-vitro Dissolution Study}

The in-vitro dissolution studies of PMDF were carried out using USP dissolution test apparatus Type-II Paddle Method (Dissolution test TDT-08L plus, Electrolab, USP) at $50 \mathrm{rpm}$. The dissolution study was conducted in $250 \mathrm{ml}$ of phosphate buffer having $\mathrm{pH} 6.8$ as a dissolution medium at $37^{\circ} \mathrm{C} \pm 0.5$ ${ }^{0} \mathrm{C}$ temperature. Optimized batches of PMDF HF\&PF were suspended in reported dissolution media. Aliquot $5 \mathrm{~mL}$ of dissolution medium was withdrawn at specified time intervals and immediately replaced with an equal volume of fresh medium. Samples were suitably diluted and analysed for percent drug release by using UV spectrophotometer (Shimadzu UV-1700 Pharmaspec, Shimadzu, double beam spectrophotometer) at $\lambda \max 425 \mathrm{~nm}$. All the tests were carried out in triplicate. $(10,20)$

\section{In-vitro Disintegration Test}

Vitro disintegration test was carried out by taking $10 \mathrm{ml}$ of water at $37^{\circ} \mathrm{C}$ placed in a petri dish having $10 \mathrm{~cm}$ diameter. The PMDF carefully positioned in the center of the petri dish and noted time required to disintegrate completely. Disintegration time of PMDF was measured in replicates $(n=6)$ and mean \pm SD values were recorded.

\section{Characterization}

Identification of drug is a part of preformulation study and prior to the development of dosage form with the drug, it is essential to determine certain fundamental physical and chemical properties of the drug molecule and other derived properties of the drug. This information will dictate many of the subsequent events and possible approaches in the development of the formulation.

\section{UV Spectroscopy}


Perindopril Erbumine is freely soluble in distilled water and sample solution of drug (concentration 10 to $60 \mu \mathrm{g} / \mathrm{ml}$ ) was prepared. Then scan the spectrum was scanned at range 200 to $400 \mathrm{~nm}$ on a UV spectrophotometer (Shimadzu-1800) and the spectrum was compared with standard spectra of drugs.

\section{Fourier transforms infra-red spectroscopy}

The FTIR study of Perindopril Erbumine was carried out to identify the functional group present in the material. For FTIR spectroscopy, Perindopril Erbumine was mixed with dried KBR in the ratio 1:100. Then the IR spectrum was taken on a FTIR spectrophotometer (IR Infinity, Shimadzu) by the DRS technique (Diffuse reluctant substance) and the result was shown in (Fig.4)

\section{Differential scanning calorimetry}

The thermal behavior of Perindopril Erbumine was examined by DSC. The DSC curve of the samples was obtained by a differential scanning calorimeter (Mettler Toledo). Each sample was placed in an aluminum pan and then crimped with an aluminum cover. The heating and cooling rate were $20^{\circ} \mathrm{C} / \mathrm{min}$ and all measurements were performed over temperature range $40-300{ }^{\circ} \mathrm{C}$.obtained result was shown in (Fig.5)

\section{Drug-Excipients Interaction Study}

\section{Differential scanning calorimetry (DSC)}

Physical mixtures of drug and excipients were filled in the prewashed vial and sealed. The sealed vial was kept at $37 \pm$ $0.5^{\circ} \mathrm{C}$ for 28 days in stability chamber. At the end of 28 days vials were removed from stability chamber and investigated for interaction study. Drug-excipient interaction study was done by using DSC. In this study thermogram of pure drug Perindopril Erbumine, Pullulan, HPMC E15, physical mixture was taken (Fig.5). The DSC curves of the samples were obtained by a differential scanning calorimeter (Mettler Toledo). Each sample was placed in an aluminum pan and then crimped with an aluminum cover. The heating and cooling rates were $20^{\circ} \mathrm{C} / \mathrm{min}$ and all measurements were performed over temperature range $40-300^{\circ} \mathrm{C}$.
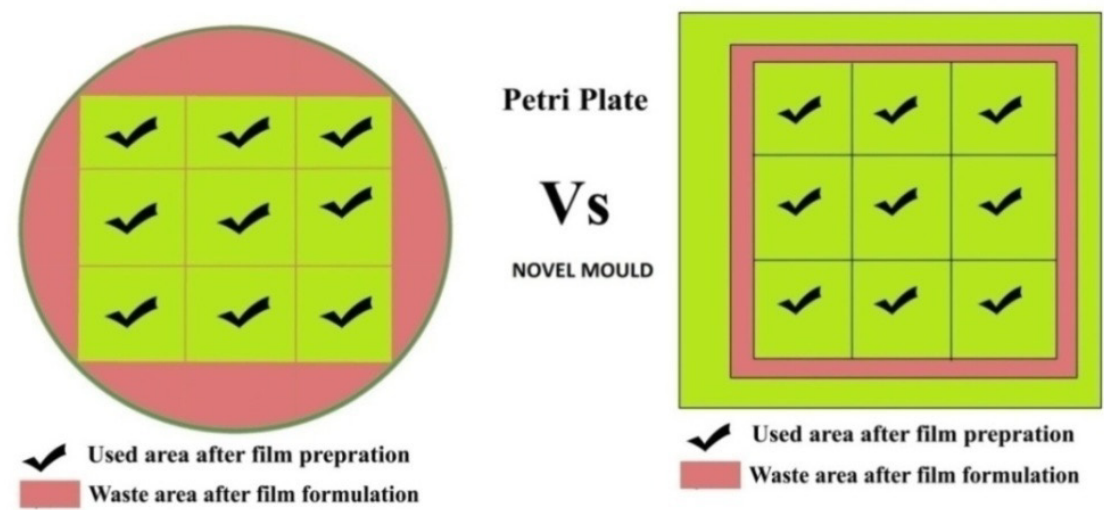

\section{Fourier transforms infrared (FT-IR) spectroscopy}

IR spectroscopy was also used to determine the molecular interaction between polymer and drug (Fig.4). Infrared spectra of Pure drug, Pullulan, HPMC E15 physical mixture were obtained using FT-IR spectrophotometer (IR Infinity, Shimadzu) by the DRS technique (Diffuse reluctant substance).

\section{Surface morphology}

Sample of PMDF prepared by fracturing the films in liquid nitrogen, mounted on aluminum stubs, and sputter coated with platinum and surface morphology of PMDF was studied by scanning electron microscopy (SEM) with magnification of X25,000. (JEOL 5400, Tokyo, Japan).

\section{Stability Study}

The stability study of PMDFs was carried out according to the ICH guidelines for zones III and IV. The formulations were stored at $40 \pm 2{ }^{\circ} \mathrm{C} / 75 \pm 5 \% \mathrm{RH}$ for 3 months by storing the samples in a stability chamber. At the end of $1,2 \& 3$ month PMDFs were tested for thickness, drug content, disintegration time.(21)

\section{Result and Discussion}

Placebo MDFs were prepared by widely used solvent casting method. Some defects were observed in MDF like deposition of solution at the edges of petri dish, cracking of film, un-uniform distribution of excipients, variation in thickness and wastage during cutting of film, show at (Fig.1) In this method regular circular shape of petri dish was used as mold, It gives only $55 \%$ practical yield and $45 \%$ loss during cutting of square shape film, comparison of design novel mold for MDF (Fig.3) gives 90\% practical yield and $10 \%$ loss. Therefore, square shape novel mold were designed for casting of the film having inner diameter $20 \times 20 \mathrm{~cm}$ in area, show at (Fig.2). This will reduce the wastage of active ingredient and other excipients. Forceps, Roll and Draw scale, water leveling meter were used to reduces losses occurs during cutting and pill-out of film, which leads to reduce the cast of films and to achieve uniformity of MDF thickenss.

Figure 3. Comparison of design novel mould \& Petri plate for casting MDF 


\section{Formulation and evaluation of mouth dissolving film}

Placebo MDF (H1-H10 and P1-P10) batches were prepared on specially designed novel mould by modified solvent casting method and study the effect of film forming agent (HPMC E-15 and Pullulan) in different concentration in the range of $125-750 \mathrm{mg}$ and $450-950 \mathrm{mg}$ respectively on film formation, From result, it was reveals that, as concentration of HPMC E-15 and Pullulan increased as film the disintegration and dissolution time were increased but transparency of film decreased with increased in concentration of film forming agent. MDF Batch H1 and P1 unable to peel out at concentration $100 \mathrm{mg}$ and 350 $\mathrm{mg}$. Hence, batches H2 contain 125mg of HPMC E-15 and P2 contain $450 \mathrm{mg}$ of Pullulan were optimized on the basis of low disintegrating time and low dissolution time, good transparency and sufficient peel out properties. Therefore, this two batches were selected for further study, shown in (Table 3).

Table 3. Evaluation of film forming agent HPMC E15 and Pullulan

\begin{tabular}{|c|c|c|c|c|c|}
\hline $\begin{array}{c}\text { Form- } \\
\text { ulation }\end{array}$ & $\begin{array}{c}\text { Disintegration } \\
\text { Time (sec) } \\
\text { SD (n=3) }\end{array}$ & $\begin{array}{c}\text { Dissolution } \\
\text { Time (sec) } \\
\text { SD (n=3) }\end{array}$ & $\begin{array}{c}\text { Form- } \\
\text { ulation }\end{array}$ & $\begin{array}{c}\text { Disintegration } \\
\text { Time (sec) } \\
\text { SD (n=3) }\end{array}$ & $\begin{array}{c}\text { Dissolution } \\
\text { Time (sec) } \\
\text { SD (n=3) }\end{array}$ \\
\hline H1 & $8 \pm 0.471405$ & $29 \pm 1.699673$ & P1 & $6 \pm 0.471405$ & $28 \pm 0.471405$ \\
\hline H2 & $\mathbf{8} \pm \mathbf{0 . 4 7 1 4 0 5}$ & $\mathbf{3 2} \pm \mathbf{0 . 4 7 1 4 0 5}$ & P2 & $\mathbf{1 0} \pm \mathbf{1 . 6 9 9 6 7 3}$ & $\mathbf{4 3} \pm \mathbf{0 . 8 1 6 4 9 7}$ \\
\hline H3 & $11 \pm 1.699673$ & $49 \pm 0.942809$ & P3 & $25 \pm 1.247219$ & $52 \pm 0.942809$ \\
\hline H4 & $22 \pm 1.247219$ & $52 \pm 1.247219$ & P4 & $41 \pm 1.699673$ & $71 \pm 0.816497$ \\
\hline H5 & $33 \pm 1.632993$ & $55 \pm 0.471405$ & P5 & $44 \pm 1.699673$ & $95 \pm 0.471405$ \\
\hline H6 & $40 \pm 0.942809$ & $60 \pm 00$ & P6 & $90 \pm 0.471405$ & $149 \pm 0.471405$ \\
\hline H7 & $47 \pm 0.471405$ & $60 \pm 2.054805$ & P7 & $117 \pm 0.816497$ & $201 \pm 1.699673$ \\
\hline H8 & $48 \pm 0.816497$ & $64 \pm 1.247219$ & P8 & $157 \pm 4.966555$ & $280 \pm 2.867442$ \\
\hline H9 & $50 \pm 0.471405$ & $75 \pm 2.054805$ & P9 & $202 \pm 0.942809$ & $301 \pm 1.414214$ \\
\hline H10 & $55 \pm 2.357023$ & $90 \pm 2.054805$ & P10 & $223 \pm 0.816497$ & $355 \pm 2.054805$ \\
\hline
\end{tabular}

Table 4. Evaluation of Plasticizer with film forming agent

\begin{tabular}{|c|c|c|c|c|}
\hline $\begin{array}{c}\text { Bach } \\
\text { No. }\end{array}$ & $\begin{array}{c}\text { Disintegration } \\
\text { Study } \\
\text { SD }(n=3) \\
\end{array}$ & $\begin{array}{c}\text { Dissolution } \\
\text { Study } \\
\text { SD }(n=3) \\
\end{array}$ & $\begin{array}{c}\text { Tensile } \\
\text { Strength } \\
\text { SD }(n=3) \\
\end{array}$ & $\begin{array}{c}\text { Percentage } \\
\text { Elongation } \\
\text { SD }(n=3) \\
\end{array}$ \\
\hline A1 & $12 \pm 1.41421$ & $40 \pm 0.81649$ & 3.73761 & 21.5 \\
\hline $\mathbf{A 2}$ & $13 \pm 0.470140$ & $49 \pm 0.47140$ & 3.743496 & $22.5 \%$ \\
\hline $\mathbf{A 3}$ & $14 \pm 0.01$ & $45 \pm 0.47140$ & 3.81609 & $35.5 \%$ \\
\hline A4 & $14 \pm 0.42411$ & $45 \pm 0.81647$ & 3.811185 & $32.5 \%$ \\
\hline A5 & $14 \pm 0.57735$ & $49 \pm 1.24729$ & 3.808733 & $24.5 \%$ \\
\hline A6 & $16 \pm 0.471405$ & $50 \pm 0.471405$ & 3.771945 & $24 \%$ \\
\hline A7 & $30 \pm 0.81649$ & $65 \pm 0.47145$ & 3.751344 & $33.5 \%$ \\
\hline A8 & $40 \pm 0.94280$ & $74 \pm 0.47145$ & 3.743496 & $23.5 \%$ \\
\hline B1 & $11 \pm 0.81647$ & $50 \pm 0.87977$ & 3.792546 & $31 \%$ \\
\hline B2 & $13 \pm 0.00$ & $48 \pm 0.81647$ & 3.796961 & $32.5 \%$ \\
\hline B3 & $13 \pm 0.47545$ & $56 \pm 0.81648$ & 3.795489 & $32 \%$ \\
\hline B4 & $14 \pm 0.81647$ & $54 \pm 0.47587$ & 3.801866 & $33.5 \%$ \\
\hline B5 & $18 \pm 0.471405$ & $53 \pm 0.816497$ & 3.826391 & $38.5 \%$ \\
\hline B6 & $16 \pm 0.81649$ & $54 \pm 0.94257$ & 3.810204 & $34 \%$ \\
\hline B7 & $32 \pm 1.91274$ & $78 \pm 0.47145$ & 3.800995 & $34 \%$ \\
\hline B8 & $50 \pm 0.47145$ & $84 \pm 0.47145$ & 3.792546 & $25.5 \%$ \\
\hline
\end{tabular}


Propylene glycol and PEG-400 as a plasticizer in $10,20,30,40 \mu / \mathrm{ml}$ was added and prepared batched from (A1-A8 and B1-B8) and optimized the effect of plasticizer with a film forming agent in film formation. Plasticizer effects on the physical integrity of the film was observed after evaluation of parameters like Percentage elongation, Tensile strength, shown in the (Table 4). Dissolution time and disintegration time, Tensile strength and \% elongation were increased with increasing concentration of plasticizer, which produces soft film. Hence, batches A3 and B5 20 $\mu / \mathrm{ml}$ and $30 \mu / \mathrm{ml}$ plasticizer Propylene glycol show short disintegration time and dissolution time with sufficient Tensile strength and \% elongation and without plasticizer film show more brittleness which is easy to break, shown in (Table 4).

Table 5. Formulation of Perindopril Erbumine containing mouth dissolving films

\begin{tabular}{|c|c|c|}
\hline $\begin{array}{c}\text { Batch } \\
\text { Ingredient }\end{array}$ & HF & PF \\
\hline Perindopril (mg) & $\mathbf{7 2}$ & 72 \\
\hline HPMC E15 (mg) & $\mathbf{1 2 5}$ & 450 \\
\hline Pullulan (mg) & --- & 20 \\
\hline Propylene Glycol ( $\mathbf{m m l})$ & $\mathbf{3 0}$ & 30 \\
\hline Neotame (mg) & $\mathbf{3 0}$ & 55 \\
\hline Citric Acid (mg) & $\mathbf{5 5}$ & 0.5 \\
\hline Pine App. Flv (ml) & $\mathbf{0 . 5}$ & 0.25 \\
\hline Amaranth (mg) & $\mathbf{0 . 2 5}$ & 14 \\
\hline Dist. Water $(\mathbf{m l})$ & $\mathbf{1 4}$ & \\
\hline
\end{tabular}

Table 6. Evaluation of PMDF

\begin{tabular}{|c|c|c|}
\hline Parameters & HF & $\mathbf{P F}$ \\
\hline \multicolumn{3}{|c|}{ Physical Properties } \\
\hline Thickness & $0.01 \mathrm{~mm}$ & $0.01 \mathrm{~mm}$ \\
\hline Weight variation & $8.5 \pm 0.345$ & $15.2 \pm 0.443$ \\
\hline Content Uniformity & $99.3 \pm 0.3$ & $101.25 \pm 0.1$ \\
\hline $\mathrm{pH}$ & 6.7 & 6.7 \\
\hline Disintegrating time & $11 \pm 0.4924$ & $17 \pm 0.1125$ \\
\hline \multicolumn{3}{|c|}{ Tensile Properties } \\
\hline $\begin{array}{c}\text { Tensile Strength } \\
\left(\mathrm{N} / \mathrm{mm}^{2}\right)\end{array}$ & 3.7501 & 3.796961 \\
\hline$\%$ Elongation & $23 \%$ & $32.5 \%$ \\
\hline Tear resistance $(\mathrm{N})$ & 2.336851 & 2.51457 \\
\hline Folding endurance & 325 & 410 \\
\hline
\end{tabular}

Perindopril Erbumine containing optimized concentrations of film forming agent, plasticizer and other excipients were added and prepared HF and PF batch of specially designed novel mold by modifying solvent casting methods, shown in (Table 5). The results stated that, the all batches were acceptable in terms of weight variation $(100 \pm 10 \%)$, and drug contents are described in (Table 6). Thickness was found to be in the range $0.01-0.03 \mathrm{~mm}$, In vitro disintegration time of all MDF batches were studied and all MDF show disintegration time in $<17$ sec. In MDF; concentration of plasticizer was changed with constant film former concentration. The result reveals that batch contain $20 \mu / \mathrm{ml} \mathrm{PG}$ have less disintegration time compared to batches contain 40, 30, $20 \mu / \mathrm{ml}$ PG. It indicates that MDF are easily dissolved when placed in the mouth. The $\mathrm{pH}$ of the film is slightly acidic to facilitate saliva secretion. The tensile strength was performing to asses' strength and elasticity of the film. As the concentration of plasticizer increased tensile strength, \% elongation, tear resistance and folding endurance increased. The all MDF batches have sufficient strength and elasticity to withstand mechanical stress during transport.

Identification and confirmation of pure drug (Perindopril Erbumine) were carried out by using UV spectroscopy, infrared spectroscopy and differential scanning calorimeter. Perindopril Erbumine solution was scanned at $200 \mathrm{~nm}$ to 400 $\mathrm{nm}$, an absorbance maximum observed at $219 \mathrm{~nm}$ in $\mathrm{pH} 6.8$ phosphate buffer. FTIR principal peaks corresponds to the structural features of Perindopril Erbumine are shown in (Fig.4) and found $1743.86 \mathrm{~cm}^{-1}$ peak of confirming presence of $\mathrm{C}=\mathrm{O}$ stretching, broad peak at $2500-3000 \mathrm{~cm}^{-1}$ and peck at $1292.61 \mathrm{~cm}^{-1}$ confirm the acid group, further peak at 3111.78 with $1640.12 \mathrm{~cm}^{-1}$ confirm presence of anime with amide linkage. Peak at 1743.86 with1207. $44 \mathrm{~cm}^{-1}$ confirm the presence of the ester group. The peak at $2860.37 \mathrm{~cm}^{-1}$ confirms the presence of $\mathrm{C}-\mathrm{H}$ stretching of primary carbon. The peak at $2929.87 \mathrm{~cm}^{-1}$ confirms the presence of $\mathrm{C}-\mathrm{H}$ stretching in aromatic group. DSC thermogram of Perindopril Erbumine exhibits in (Fig.5) and found sharp exothermic peak at $128^{\circ} \mathrm{C}$ means that it has a crystalline structure corresponding to its melting and decomposition. The reported peak temperature was $125-129{ }^{\circ} \mathrm{C}$. The spectrum and thermogram of Perindopril Erbumine shows the desired peak as per reported in the USP pending monograph.

Drug-excipient interaction studies were done by using FTIR spectroscopy and used to assess the interaction between drug Perindopril Erbumine and other excipients. FT-IR spectrum drug Perindopril Erbumine, Pullulan, HPMC E15 and their physical mixtures was shown in (Fig.4). The principal peaks corresponds to the structural features of Perindopril Erbumine are observed that, Peak of 1743.86 $\mathrm{cm}^{-1}$ confirms presence of $\mathrm{C}=\mathrm{O}$ stretching, broad peck at $2500-3000 \mathrm{~cm}^{-1}$ and peck at $1292.61 \mathrm{~cm}^{-1}$ confirm the acid group, further peak at 3111.78 with $1640.12 \mathrm{~cm}^{-1}$ confirm presence of anime with amide linkage. Peak at 1743.86 with1207. $44 \mathrm{~cm}^{-1}$ confirm the presence of the ester group. The FT-IR spectrum of the Pullulan is characterized by broad bands at $3150-3650 \mathrm{~cm}^{-1}$ and $1031.92 \mathrm{~cm}^{-1}$ due to aromatic $\mathrm{O}-\mathrm{H}$ stretching vibrations, $1118.71 \mathrm{~cm}^{-1}$ due to vibration of C-O-C groups. The FT-IR spectrums of the HPMC E15 contain broad peak at 3350.36 region to peck at $1012.63 \mathrm{~cm}^{-1}$ due to aromatic $\mathrm{O}-\mathrm{H}$ stretching, broad peak at 2835.36-2927.94 $\mathrm{cm}^{-1}$ region due to $\mathrm{C}-\mathrm{H}$ and $\mathrm{C}-\mathrm{H}_{2}$ vibrations. Any sign of interaction would be reflected by changes in the characteristic peaks of Perindopril Erbumine, depending on the extent of interaction (Bramhane 2011). The 
FTIR spectra of the physical mixtures did not show any significant shifts in principal peak with respect to the FTIR spectra of the Perindopril Erbumine. Hence study reveals that there is no any physicochemical interaction between Perindopril Erbumine and excipients. DSC of drug perindopril Erbumine (A), Pullulan (B), HPMC E15 (C), Perindopril Erbumine: Pullulan (A: B) physical mixture and Perindopril Erbumine: HPMC E15 (A: C) physical mixture is shown in (Fig.5). The DSC curve of Perindopril Erbumine exhibiting a sharp endothermic peak at $128^{\circ} \mathrm{C}$ indicated melting point. Whereas Pullulan and HPMC E 15 shows melting peaks at 107.5 and $112{ }^{\circ} \mathrm{C}$. Thermogram of Perindopril Erbumine: Pullulan physical mixture showed an endothermic peak of pullulan at $109.1^{\circ} \mathrm{C}$ followed by broad endotherm of Perindopril Erbumine at $124.51^{\circ} \mathrm{C}$. Thermogram of Perindopril Erbumine: HPMC E15 physical mixture showed an endothermic peak of HPMC E15 at 114.9 ${ }^{0} \mathrm{C}$ followed by broad endotherm of Perindopril Erbumine at $124.79{ }^{\circ} \mathrm{C}$. The peak of Perindopril Erbumine in the physical mixture shifted to lower scale with broad endotherm indicates the conversion of crystalline to amorphous.

Optimized batch (HF and PF) of Perindopril Erbumine containing Mouth dissolving films was prepared on specially designed novel mold by modifying solvent casting methods and in-vitro release study of two batches was carried out at
pH 6.8 at $37^{\circ} \mathrm{C} \pm 0.5^{\circ} \mathrm{C}$ and shows maximum drug release more than $90 \%$ within in 4 min. and drug release optimized batch HF and PF showed 98.60 and $99.60 \%$ in $3 \mathrm{~min}$ respectively, shown in (Fig.7) Surface morphological study was carried out on scanning electron microscopy with 50000 $\mathrm{x}$ magnification values at $5 \mu \mathrm{m}$ lengths. The image was scanned from both upper surface (A) and lower surface (B). Resulted film containing Perindopril Erbumine oral MDF was clear and colorless in nature. Smooth surface with some little pores and with few scratches or transverse striations were shown in (Fig.6)

Lower surface (B) is shown smooth as compare to upper surface (A) because of during formulation glass slide more smooth surface. Scanned image also shows a clear image, therefore it should be conclude total drug and excipients was dissolved and uniformly distributed within the formulation. The stability of optimized formulation HF was monitored up to 3 months at stress temperature and normal humidity conditions $\left(40^{\circ} \mathrm{C} \pm 75 \% \mathrm{RH}\right)$. Periodically (initial, 1, 2, 3 months) samples were removed and evaluated by different parameters like thickness, content uniformity, disintegration test, weight variation.. There were no major changes observed during stability studies of Perindopril Erbumine containing mouth dissolving film. The result are summarized in (Table 7).

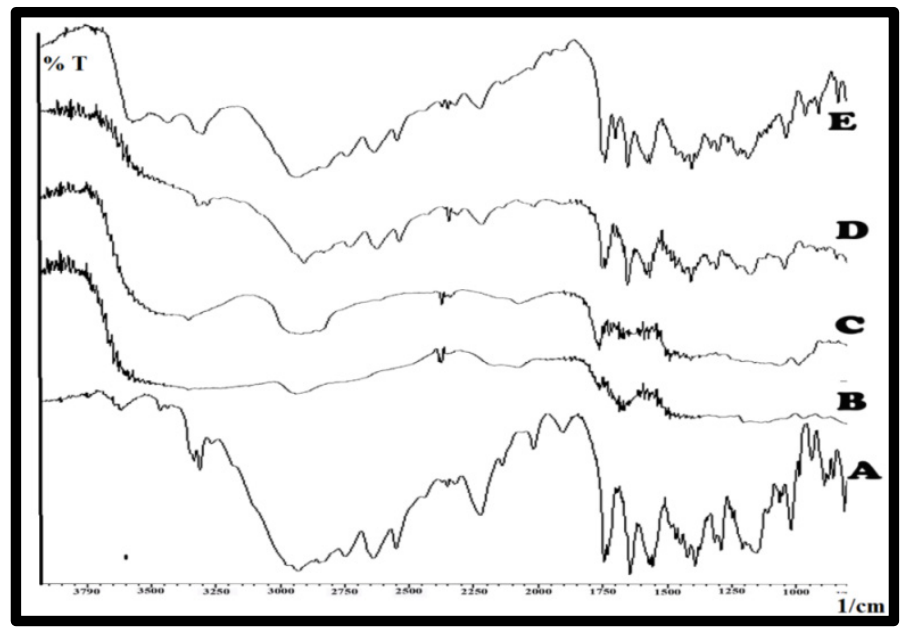

Figure 4. FTIR spectra for Drug-Interaction study, $A=$ Perindopril Erbumine, $B=$ Pullulan, $C=$ HPMC E-15, $D=$ Mixture of Perindopril Erbumine with Pullulan and E= Perindopril Erbumine with HPMC E-15.

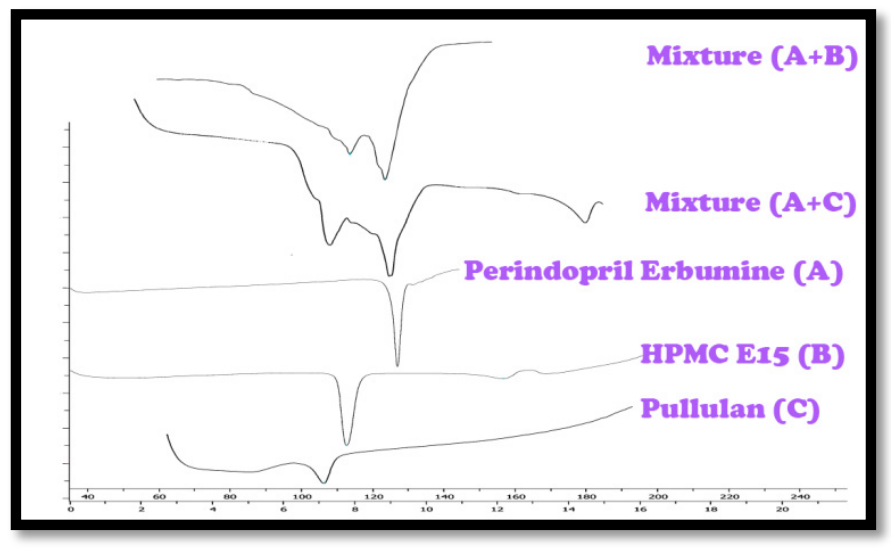

Figure 5. DSC thermogram of Drug-Excipients Interaction Study 

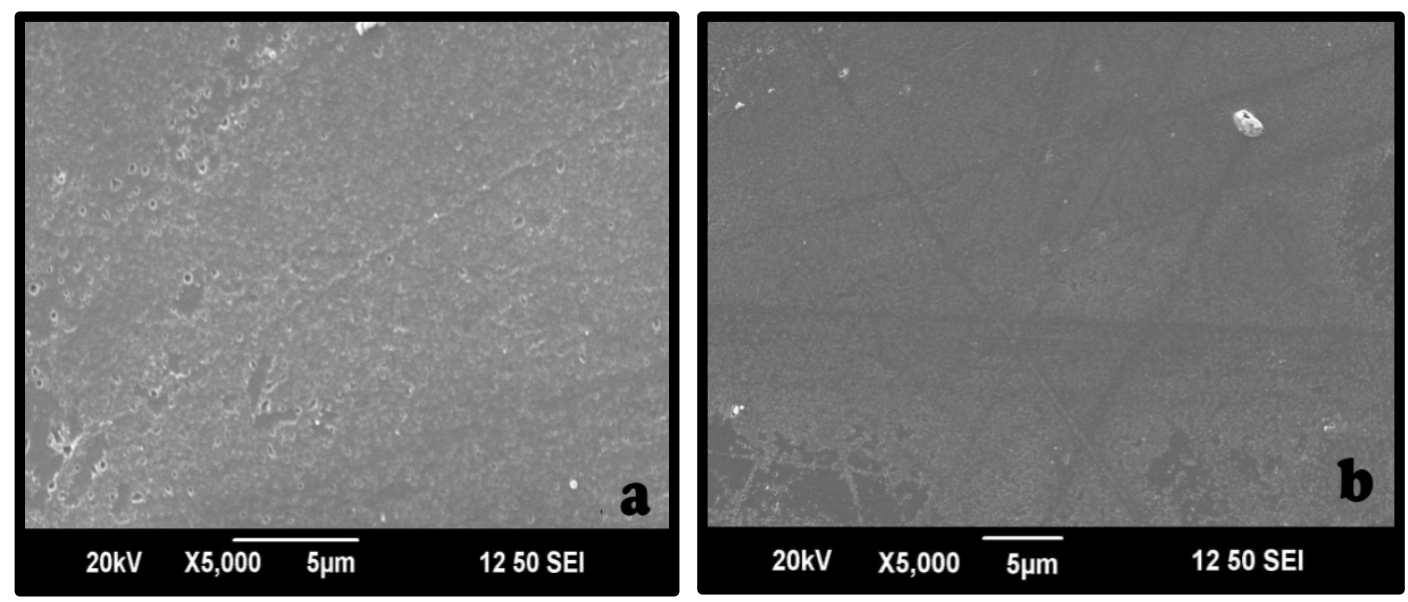

Figure 6. SEM of MDF (a) upper surface and (b) lower surface

Table 7. Stability study of PMDF (HF)

\begin{tabular}{|c|c|c|c|c|}
\hline $\begin{array}{c}\text { Evaluation } \\
\text { Parameters }\end{array}$ & Before Stability & $\begin{array}{c}\text { After 1 Month } \\
\text { Storage }\end{array}$ & $\begin{array}{c}\text { After 2 Month } \\
\text { Storage }\end{array}$ & $\begin{array}{c}\text { After 3 Month } \\
\text { Storage }\end{array}$ \\
\hline Thickness & $0.01 \mathrm{~mm}$ & $0.01 \mathrm{~mm}$ & $0.01 \mathrm{~mm}$ & $0.01 \mathrm{~mm}$ \\
\hline Content Uniformity & $99.3 \pm 0.3$ & $99.3 \pm 0.3$ & $99.3 \pm 0.3$ & $99.3 \pm 0.3$ \\
\hline Disintegration Time & $10 \pm 0.4726$ & $10 \pm 0.4790$ & $10 \pm 0.4826$ & $10 \pm 0.4826$ \\
\hline Weight variation & $8.9 \pm 0.3$ & $8.9 \pm 0.3$ & $8.9 \pm 0.6$ & $8.8 \pm 0.3$ \\
\hline
\end{tabular}

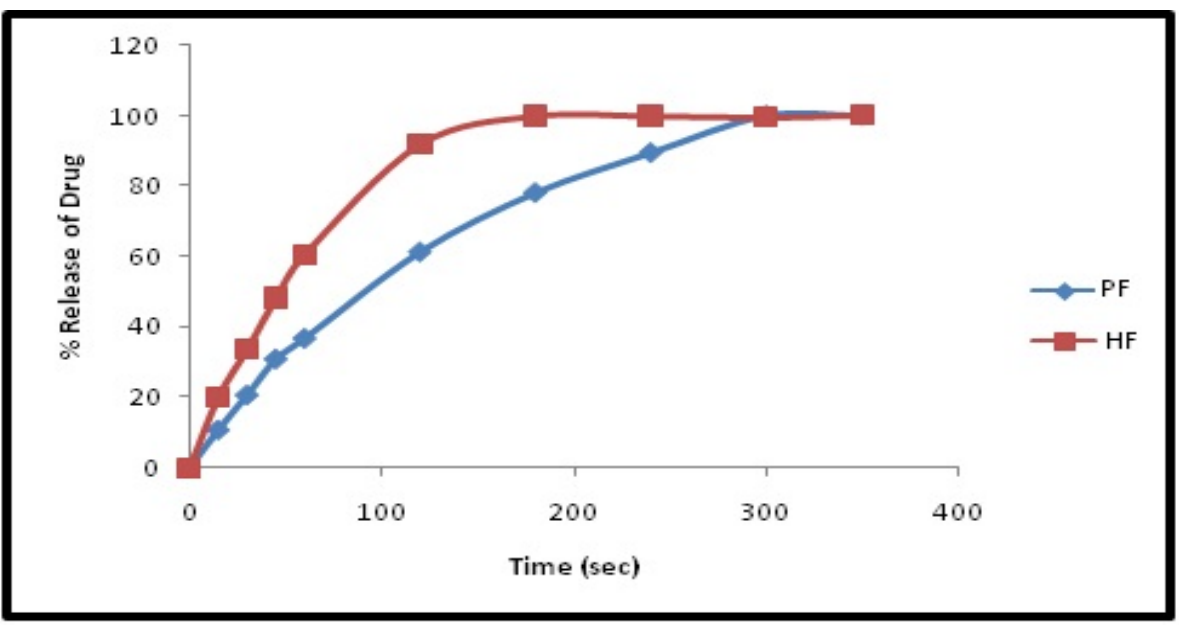

Figure 7. In-vitro release study of PMDF

\section{Conclusion}

From this study it can be concluded that, specially designed novel mold was found to be more effective than petri dish which overcome the problems occurs during the casting of mouth dissolving films. Prepared Perindopril Erbumine containing mouth dissolving film (MDF) with HPMC E-15 125mg and Propylene Glycol $30 \mu \mathrm{ml}$ as plasticizer concentration was found to be optimized when compared with Pullulan on the basis of physical evaluation parameters like weight variation, drug, thickness in the range $0.01-0.03 \mathrm{~mm}$, disintegration time in $<17 \mathrm{sec}$. And release of drug from film in $<60 \mathrm{sec}$ and other parameters were found within acceptable limits and various new equipments were used first time in PMDFs preparation for cutting, pill-out and water level indicator for balancing novel mold in the oven, which was widely used in other field like engineering and physics. Especially design mold for casting of the film was found to be more efficient than regular petri dish due to easily scale up and avoid problems occurs during preparation 
of stable mouth dissolving film which leads to reduce the wastage of active ingredients and excipients.

\section{Acknowledgments}

Authors thankful to Mr. Mohan Kale, Marketing Manager Gangwal Chemical Pvt. Ltd, Mumbai India for generously gifted Pullulan polymer and Prof. Vinod J Mokale, Asst. Prof.\& Head, Department of M.Tech (Pharm), UICT, North Maharashtra University, Jalgaon for providing FESEM, XRD facility.

\section{Conflicts of Interest}

No Conflicts of Interest

\section{REFERENCES}

[1] Gaisford S, Vermaa A, Saunders M, Paul G. R, Monitoring Crystallisation Of Drugs From Fast-Dissolving Oral Films With Isothermal Calorimetry Int J Pharm 380 (2009) 105 111.

[2] Reddy D, Pillay V, Rapidly Disintegrating Oramucosal Drug Delivery Technologies Pharm Dev Technol, 2009; 14(6): 588-601.

[3] Doaa Ahmed El-Setouhy And Nevine Shawky Abd El-Malak Received, Formulation Of A Novel Tianeptine Sodium Orodispersible Film, AAPS Pharmscitech, Vol. 11, No. 3, September 2010 .

[4] Lakshmi PK, Sreekanth J, Sridharan A, Formulation Development Of Fast Releasing Oral Thin Films Of Levocetrizine Dihydrochloride With Eudragit ${ }^{\circledR}$ Epo And Optimization Through Taguchi Orthogonal Experimental Design, Asian J. Pharm, Year : 2011 , Volume : 5 , Issue : 2,Page : 84-92.

[5] Prabhu, P. Et Al., 2011. Formulation And Evaluation Of Fast Dissolving Films Of Levocitirizine Di Hydrochloride. Arch Pharma Pract., 1(2), .99-104.

[6] Cilurzo F, Minghetti P,Buratti S, Selmin F, Montanari L, Nicotine Fast Dissolving Films Made Of Maltodextrins: A Feasibility Study, AAPS Pharmscitech, Vol. 11, No. 4, December 2010.

[7] Kulkarni PK, Dixit M, Gunashekra K, Shahnawaz A, Singh M N And Kulkarni A, Formulation And Evalution Of Mouth Dissolving Film Containing Rofecoxib, International Journal Of Pharmacy ISSN 2230-8407 IRJP 2(3) 2011 273-278.

[8] Kulkarni A. S., Deokule H.A., Mane M.S. And Ghadge D. M.,Exploration Of Different Polymers For Use In The Formulation Of Oral Fast Dissolving Strips, Journal Of Current Pharmaceutical Research 2010; 2(1): 33-35.
[9] Mutalik S, Nayak U, Shavi G, Armugam K, Pandey S, And Nayanabhirama U, Development Of Mucoadhesive Buccal Films For The Treatment Of Oral Sub-Mucous Fibrosis:A Preliminary Study, PHARM DEV TECHNOL, 2009; 14(2): 199-207.

[10] Arya A, Chandra A, Sharma V And Pathak K Fast Dissolving Oral Films: An Innovative Drug Delivery System And Dosage Form, International Journal Of Chemtech Research, CODEN( USA): IJCRGG ISSN : 0974-4290, Vol.2, No.1, Pp 576-583, Jan-Mar 2010.

[11] Morales J. O., McConville J. T., Manufacture and characterization of mucoadhesive buccal films., European Journal of Pharmaceutics and Biopharmaceutics 77 (2011) $187-199$.

[12] M Koland, VP Sandeep, And NR Charyulu, Fast Dissolving Sublingual Films Of Ondansetron Hydrochloride: Effect Of Additives On In Vitro Drug Release And Mucosal Permeation, , J Young Pharm, . 2010 Jul-Sep; 2(3): 216-222. Doi: 10.4103/0975-1483.66790 PMCID: PMC2964757.

[13] Mishra R And Amin A, Formulation And Characterization Of Rapidly Dissolving Films Of Cetirizine Hydrochloride Using Pullulan As A Film Forming Agent, Indian Journal Of Pharmaceutical Education And Research, Ind J Pharm Edu Res, Jan-Mar, 2011/ Vol 45/ Issue 1.Association

[14] Kunte, S. and Tandale, P., 2010. Fast Dissolving Strips $\square: \mathrm{A}$ Novel Approach For The Delivery Of Verapamil. J. Pharm. Bioall, 2(4), Pp.2010-2013.

[15] Sridevi N, Jahnavi G, Sekaran C B, Spectrophotometric analysis of antihypertensive drug in bulk and tablets using bromophenol blue. Der Pharmacia Lettre, 2012,4(1):159-169.

[16] Yellanki SK, Jagtap S, And Masareddy R, Dissofilm: A Novel Approach For Delivery Of Phenobarbital; Design And Characterization, J Young Pharm. 2011 Jul-Sep; 3(3): 181-188.Doi: 10.4103/0975-1483.83756.

[17] Cilurzo F, Minghetti P, Selmin F, Montanari L, Fast Dissolving Films Made Of Maltodextrins, Eur J Pharm Biopharm 70 (2008) 895-900.

[18] Karale AM, Minghetti P, Buratti S, Montanari L, Diclofenac Fast-Dissolving Film: Suppression Of Bitterness By A Taste-Sensing System, Drug Dev Ind Pharm, 2011, 37(3): 252-259.C 2011 Informa Healthcare USA, Inc. ISSN 0363-9045 Print/ISSN 1520-5762 Online.

[19] Dixit R.P,. Puthli S.P,,Oral Strip Technology: Overview And Future Potential, J Control Release 139 (2009) 94-107.

[20] Sharma. R., Rajput, M., Prakash, P., 2011. Fast Dissolving Drug Delivery System - A Review, IRJP. 2(11), Pp.21-29.

[21] Dinge A And Nagarsenker M Formulation And Evaluation Of Fast Dissolving Films For Delivery Of Triclosan To The Oral Cavity, AAPS Pharmscitech, Vol. 9, No. 2, June 2008 ( 2008) DOI: 10.1208/S12249-008-9047-7. 